\title{
On the Importance of Physical Fitness Training in College Basketball
}

\author{
Li Lidao
}

\begin{abstract}
Sports Department of Oxbridge College, Kunming University of Science and Technology, Kunming, Yunnan 650106
\end{abstract}

Keywords: College basketball; Physical Training; Importance

\begin{abstract}
With the influence of social economy, living level of people is growing, and while they meet basic needs, people began paying attention to health that sport becomes an important role in people's life. As a comprehensive sports item, basketball is not only acquires good physical quality, it also needs quick reaction and corresponding speed. In every college, basketball has became an vital fraction among sports teaching item, however, according to present condition, most colleges neglect the importance of basketball physical strength, and they treat it as a normal sports. Therefore, we are going to discuss the importance of physical training in college basketball, and come up with related corrective actions by analyzing present situation.

As a popular sports item, there are three words could represent the traits of basketball: score, technique and speed. To be specific, it means that basketball sets score as final aim, and basing on it, players could make full use of various skillful technique and advantages in speed, to win over score. College students are the main group to make our country develop better, however, according to nowadays, the amount of weakness and fatness among students is not less, and the trend of physical condition is decreasing. In order to emphasis the importance of physical training of basketball among college students, it is meaningful to explore it.
\end{abstract}

\section{Trait of Physical Training in College Basketball}

To Strengthen Physical Quality. Among the traits to develop basketball physical training in college students, strengthening physical quality must be the first one. And among the technique points of basketball, the advantages of explosive effort and reaction speed is the vital support, no matter dribbling or defense, shooting or rebounding. During the physical training, students should develop their reaction speed with comprehensive field and transform actions to cope with the complex basketball field, speeding up and moving quickly. From present basketball activity, the rhythm of dribbling and defense are very quick, and in order to adapt these features, it is needed to emphasize the speed of players.

Physical Training Combined Traits. In every basketball match, if one wants to win, it should use flexible defense and attack to adapt the opposite's movements, and also needs constant moving to reach a nice position, and then grasp the chance of shooting. By that, we find basketball is not only asks sufficient energy of players, it also acquires tacit agreements with each other. Physical training could not only promote the players, it is also the important part to improve strategy and gets high score. Basing on it, strategic training is vital, we should combine both and thus promote the final effect.

Personal Features. With the promoting of educational revolution, the targeted teaching method for students could be the important way of improving educational effects, same as physical training in basketball. Because every student has different physical quality, the position they stay during the matches is different, and therefore targeted training for improving comprehensive physical training has been the great feature of players. In the actual training, physical training plan to every player is different, and thus to consider every individual condition which lead to a whole advancing.

\section{The Importance of Physical Training in College Basketball}

To Improve the Physical Quality and Technique. To improve physical quality of students and to balance every organ in the body, students should take physical training in college basketball as aim, 
and thus students could face harder basketball activity. As for players, an important condition to keep going is a healthy physical quality. And for people who are not players, a fine body condition could help them go ahead. During matches, players with well physical quality could use every technique and never be afraid of any sudden issue. However, to strengthen physical training could increase the immune ability which could decrease illness, thus students could live healthier and happier ${ }^{[1]}$.

To Strengthen the Willpower of Students. As we all known, most college students are born in one-child family, such family is used to grant whatever their kids request, thus with a long-term influence, those college students usually are weak in willpower which hinder them to face difficulty, and in the long run, they will restrict the development of our country. However, physical training in basketball could reach the training aim by high-intense exercise, which means college students should repeat corresponding movements, and improve their speed and flexibility. Thus, during the specific exercise, mental quality is also a test for college students. A powerful mental quality has great influence for their future life and career ${ }^{[2]}$.

\section{Existing Issues in Physical Training in Present College Basketball}

As for Teachers. From present condition, in college campus, most teachers those who teach physical teaching in basketball do not have professional quality, imbalance in teaching resource is a vivid problem. During physical training stage, teachers usually pick freestyle activity, and they do not operate targeted and systematic conduction to students. Therefore, students lack related conduct, and they could not exercise correctly which lead to bad outcome, making basketball training too form ${ }^{[3]}$. Otherwise, each college also lacks further training for basketball teachers, thus they continue the traditional teaching. It is the important reason that they lack teaching resource.

As for Students. First of all, low level in physical quality of college students is a common phenomenon, and the original reason is that with influence of long-term test-oriented education, most parents neglect the physical training of their kids since they want their kids could attend famous university, for long time, there is no wonder that students has low-level physical quality. After entering colleges, students face high-tense physical training with sudden, which produce a avoid mood among most students, and thus they will not take part in. As for teachers, low cooperation from students will decrease the training strength, and thus the effect will not improve [4]

Secondly, with life standard raise gradually, most college students live a comfortable condition that will destroy one's willpower, it is unusual to find students with ambitious. In physical training of basketball teaching, many students use avoid attitude, some of them even make illness as an excuse to avoid basketball lesson, and in such situation, no idea for teacher. After all, the main reason is in students lacking interest of physical training, it is norm that they refuse to take part for lacking motivation $^{[5]}$.

As for Field and Equipment. At present, because of cognition, most college are unwilling to put amount capital into sports field and equipment, which to a narrow sports field and very less related equipments. There are easy outdoor basketball filed and equipment, some of them are even broken, and they still be used, however, people will get injury while using broken equipments. With long term, it will decrease the training interest of students, and thus hinder the development of students in physical training.

As for Training. There are two outstanding issues exist in exercise, first one is that training lacks system. According to present physical training in basketball, there is no system, and it is in line with traditional sports curriculum, at the very beginning of class, teacher will lead students do some easy stretching movements or bring them to run around the ground, these method are too simple that lack scientific and systematic, and it is harder for students to reach aim by such single training method ${ }^{[6]}$. Secondly, there is less training time. Every college just give one time in a week for students to operate sports class, and such class is the only physical training time, in other time, most students take their time on theory learning or something else which is not related to physical training, and thus students has less training time and could not have consciousness of it. 


\section{Solution to Physical Training in College Basketball}

To Improve Teaching Level. As for students, teacher the conductor in their learning life, and the behavior or thought of teachers will have great effect for students. In college basketball class, students depend on professional quality of their teacher to consider whether they should take physical training or not. Thus, every college should pay attention to improve teaching level of basketball teachers. First, while hiring teachers, college should combine the basketball teaching demand, acquiring teachers who are major in basketball. Secondly, as for existing teacher, college should strengthen their professional quality. The way of training is various, it could let teachers watch professional video or offer outdoor learning opportunity.

To Arouse Interest of Students. At present, college basketball teaching has some flaw, and many teachers still use traditional teaching method that every class follow by same model, it means that in the very beginning, most students will let students do warm-up by running or stretch, and then teachers will explain the contend of today which is mainly theory, and at the end of class, let students do training. Teachers usually treat these training with loose attitude, and it then lead students in a stage out of management, ${ }^{[8]}$. We all know that interest is the best teacher, thus if we want let students to cooperate teachers finishing physical training, improving teaching effect, the first thing teachers need to do is to understand the thought of college students, and break the model teaching, creating a new teaching method which will arouse learning interest of students, therefore, shaping willpower of students by physical training. For example, in class, teachers could take students do several minutes warming-up, or assign some task for students to compete with others. Students will be divided by several group with a aim, the group that with best score in physical training could win proper prize, and the worst will be given penalty like frog-jump and press-ups, with these, it could not only arouse interest of students, it also shape group credit.

To Increase Fund. The basic condition for students to finish physical training is enough training filed and equipments, thus, school should pay great attention to it by increasing capital and offer enough basic condition to students. Therefore there are two ways to assure we could get capital: first, school could apply a part of fund from country; secondly, school could cooperate with company to increase commercial sponsor. However, there are limited fund from country's educational department that is hard to support construction of training filed and equipment, compared with it, the second way will be better ${ }^{[9]}$.

To Set a Systematic Physical Training Plan. First, teachers should understand individual physical condition of every student, and then design multiple training plans to operate targeted training. While taking training, teachers should conduct, supervise and correct the mistake of students ${ }^{[10]}$. Secondly, teachers should take limited class timing with proper organization, and improve the efficiency of class as well. They also need to understand individual training condition of every student, and it will be good for their further training.

\section{Summary}

In a word, in the college sports teaching, basketball is an important class, it could not only improve physical quality of college students, it also training the willpower of them that makes sound base for their further life, learning and career. however, at present, there are kinds of reasons that lead to some issues in college basketball teaching, which present mainly in the four fraction as teacher, students, filed with equipments and training, in order to reach teaching effect of college basketball curriculum, school and teachers should pay great attention to it, improving teaching level, arousing interest of students, to increase capital and set systematic physical training plan for students, thus to promote physical quality of students, improving teaching efficiency of college basketball.

\section{Reference}

[1] Chen Jinyi. Problems and Countermeasures of Physical Training in Basketball Training [J]. Journal of Changchun Teachers College, 2015(2):62-64. 
[2] Zhong Si. Analysis of Physical Training and Teaching Status in College Basketball Classes [J].Sport and Technology,2016(14):201-202.

[3] Fang Chunlei. The importance of Physical Training in College Sports Basketball Teaching [J].Sports Time,2017(13):138.

[4] Che Ruirui. On the Importance and Problems of Physical Training for College Basketball Players [J]. Sports Time,2017(4):126.

[5]Jie Xi. Problems and Countermeasures in Physical Training of Basketball in Colleges and Universities [J].Sports,2017(4):21-22.

[6]Li Mingze. Analysis of Basketball Physical Training Skills in College Physical Education [J]. Sports Time,2017(15):126,144.

[7]Wangxin. Analysis and Research on Scientific Fitness Training of Jiangsu Men's Basketball Team [D].Su Zhou University,2016.

[8]Lv Chenglong, Zhang Zhongzi. On the importance of physical training in basketball training [J]. Heilongjiang Science and Technology Information, 2017(11):102.

[9] Tan Xiaowei. A Study on the Physical Training Method of Basketball in College Physical Education [J]. Contemporary Sports Technology,2017(18):60-61.

[10] Zhang Ming. On the Importance of Physical Fitness Training in College Basketball [J]. New Curriculum Learning,2015(05):111. 